\title{
Induced Normothermia After Severe Traumatic Brain Injury: A Prospective Observational Pilot Safety and Feasibility Study
}

\author{
Farid Sadaka ${ }^{\mathrm{a}, \mathrm{b}}$, Katie Krause ${ }^{\mathrm{a}}$, Marianne Tow ${ }^{\mathrm{a}}$, Mary Wilcox ${ }^{\mathrm{a}}$, Jacklyn O’Brien ${ }^{\mathrm{a}}$
}

\begin{abstract}
Background:: Early hyperthermia following traumatic brain injury (TBI) is associated with worsened neurologic outcomes; however, eliminating fever has not been adequately studied. We sought to explore the safety and feasibility of induced normothermia using advanced fever control (AFC) in severe TBI patients.
\end{abstract}

Methods:: Eight patients underwent AFC with a surface cooling device for 96 hours, and four patients underwent conventional fever control (CFC). Average daily fever burden (FB) was calculated as the time and extent $\left({ }^{\circ} \mathrm{C} \times\right.$ hours $)$ above $37^{\circ} \mathrm{C}$. Shivering was evaluated hourly by the bedside shivering assessment scale (BSAS, 0 - 3) and BSAS $>0$ was treated using a stepwise protocol.

Results:: FB was lower for the AFC vs. CFC group: 4.0 vs. $7.0(\mathrm{P}=$ $0.2)$ for day $1,4.3$ vs. $7.7(\mathrm{P}=0.1)$ for day $2,3.6$ vs. $5.3(\mathrm{P}=0.5)$ for day $3,4.2$ vs. $4.8(\mathrm{P}=0.7)$ for day 4 respectively. BSAS $>0$ developed more often in the AFC group (130 times) than the CFC group (two times).

Conclusion:: Induced normothermia was associated with less FB and more interventions to treat shivering compared to CFC in severe TBI patients. A large prospective randomized outcome trial of AFC vs. CFC is warranted.

Keywords: Traumatic brain injury; TBI; Fever; Normothermia

\section{Introduction}

Traumatic brain injury (TBI) is a major source of death and severe disability worldwide. In the USA alone, this type of in-

Manuscript accepted for publication August 13, 2014

${ }^{a}$ Mercy Hospital St Louis; St Louis University, MO, USA

${ }^{\mathrm{b}}$ Corresponding Author: Farid Sadaka, $621 \mathrm{~S}$. New Ballas Rd, Suite 4006B, St.

Louis, MO 63141, USA. Email: farid.sadaka@mercy.net

doi: http://dx.doi.org/10.14740/jnr283w jury causes 290,000 hospital admissions, 51,000 deaths, and 80,000 permanently disabled survivors $[1,2]$.

Fever $\left(>38^{\circ} \mathrm{C}\right)$ occurs in up to $67 \%$ of patients with TBI in the first $72 \mathrm{~h}$ [3]. As in ischemia-reperfusion injuries, the acute post-injury period in TBI is characterized by several pathophysiologic processes that start in the minutes to hours following injury and may last for hours to days. These result in further neuronal injury and are termed the secondary injury. Cellular mechanisms of secondary injury include all of the following: apoptosis, mitochondrial dysfunction, excitotoxicity, disruption in ATP metabolism, disruption in calcium homeostasis, increase in inflammatory mediators and cells, free radical formation, DNA damage, blood-brain barrier disruption, brain glucose utilization disruption, microcirculatory dysfunction and microvascular thrombosis [4]. All of these processes are temperature dependent; they are all aggravated by fever [4]. Hyperthermia following TBI is associated with a longer ICU length of stay and worsened neurologic outcomes [5-10]. In addition, brain temperatures are reported to be $1.5-2{ }^{\circ} \mathrm{C}$ higher than core temperature (measured by rectal probe) [11, 12]. Thus, brain could be febrile when core temperature is considered normal.

This is a prospective observational pilot study to evaluate the feasibility and safety of a protocol where advanced surface cooling is used in patients with severe TBI $(\mathrm{GCS}<9)$ on admission to the NeuroTrauma ICU (NTICU) to evaluate induced normothermia (prophylactic maintenance of bladder temperature between 36 and $36.5^{\circ} \mathrm{C}$ ) as compared to conventional fever control (CFC).

\section{Materials and Methods}

We prospectively randomized consecutive patients with severe TBI admitted to our NTICU between June 2012 and December 2013. Our 16 bed NTICU is staffed by intensivists (board certified by the American Board of Internal Medicine in Internal Medicine and Critical Care Medicine and certified by the United Council of Neurologic Subspecialties in Neurocritical Care) $24 \mathrm{~h} /$ day.

We excluded patients less than 18 years of age, pregnant, with bleeding disorders, hepatic encephalopathy, spinal cord injury, temperature $>38{ }^{\circ} \mathrm{C}$ prior to randomization, blood alcohol level $(\mathrm{BAL})>250 \mathrm{mg} / \mathrm{dL}$, participating in other research 
Table 1. Baseline Characteristics of Traumatic Brain Injury Patients

\begin{tabular}{llll}
\hline & CFC & AFC & P-value \\
\hline $\mathrm{n}$ & 4 & 8 & \\
Age, years, \pm SD & $56(32)$ & $46(18)$ & 0.5 \\
GCS, \pm SD & $6.2(3.7)$ & $5.9(2.0)$ & 0.8 \\
Gender, male, n, \% & $3(75)$ & $6(75)$ & 1.0 \\
Mechanical ventilation, days, SD & $7.8(1.7)$ & $8.0(5.0)$ & 1.0 \\
Patients on vasopressors & $3(75)$ & $6(75)$ & 1.0 \\
\hline
\end{tabular}

trials, inability/unwilling to obtain informed consent, terminal illness (not expected to survive 3 - 6 months), or not expected to survive $24 \mathrm{~h}$. We excluded 10 patients (six with temperature $>38{ }^{\circ} \mathrm{C}$ prior to randomization, two with BAL $>250 \mathrm{mg} / \mathrm{dL}$, and two on whom consent was not obtained). We randomized a total of 12 patients (four patients to the CFC group and eight patients to the advanced fever control (AFC) group). The study and consent form were approved by our Institutional Review Board. Consent was obtained from power of attorney or next of kin.

All CFC and AFC patients underwent randomization prior to the development of fever (temperature $\geq 38.0{ }^{\circ} \mathrm{C}$ ). In the CFC group, fever was treated with acetaminophen, $650 \mathrm{mg}$ every 4 - 6 h orally, with or without the use of a water-circulating cooling blanket. In the AFC group, an advanced surface cooling device (Arctic Sun; Medivance, Inc., Louisville, CO, USA) was applied after randomization with target temperature of $36.5^{\circ} \mathrm{C}$ (with the aim to prevent development of fever) for $96 \mathrm{~h}$. Temperature was recorded hourly using a bladder temperature probe.

All patients underwent a prospective collection of baseline clinical, laboratory, and demographic characteristics (Table 1). Data collected over the initial 96-h period included blood sugars, blood pressures, hypoxia episodes, vasopressor requirements, sedatives, interventions for shivering, and hourly temperatures. Shivering was assessed every $60 \mathrm{~min}$ (every $30 \mathrm{~min}$ in case of documented shivering) using the bedside shivering assessment scale (BSAS) (Fig. 1) that has been previously validated [13]. BSAS score can be $0,1,2$, or 3 . BSAS $>0$ was treated using a protocolized stepwise approach (Fig. 2).

Fever burden $\left(\mathrm{FB},{ }^{\circ} \mathrm{C} \times \mathrm{h}\right)$ was calculated hourly by sub- tracting each patient's recorded temperature from $37.0{ }^{\circ} \mathrm{C}$. Mean ( \pm standard deviation (SD)) hourly FBs were calculated for each day for 4 days and analyzed for any difference between $\mathrm{AFC}$ and $\mathrm{CFC}$ patients.

Although this is a feasibility and safety and not an outcome study, outcomes recorded at hospital discharge were CT scan progression, mortality, discharge location, Glasgow outcome scale (GOS), and number of times BSAS $>0$. Neurologic outcome was scored according to the five-category GOS [14] at hospital discharge for each patient. Good outcome was defined as GOS 4 - 5. The two groups were compared by Pearson Chi-squared and Fisher's exact test to analyze statistical significance. Mean, SD and P-value were reported for each comparison.

\section{Results}

FB in hours was lower for the AFC group vs. CFC group: 4.0 $( \pm 3.2)$ vs. $7.0( \pm 5.2)(\mathrm{P}=0.2)$ for day $1,4.3( \pm 3.5)$ vs. 7.7 $( \pm 2.9)(\mathrm{P}=0.1)$ for day $2,3.6( \pm 2.9)$ vs. $5.3( \pm 6.0)(\mathrm{P}=0.5)$ for day $3,4.2( \pm 3.3)$ vs. $4.8( \pm 4.6)(\mathrm{P}=0.7)$ for day 4 respectively (Table 2, Fig. 3). CT showed improvement in the AFC group and worsening in the CFC group as read by a blinded radiologist. In the AFC group, no patients died, 37.5\% were discharged to long-term acute care facility (LTAC), $62.5 \%$ to rehab facility, and $12.5 \%$ had good GOS (4 - 5); in the CFC group, $25 \%$ died, $25 \%$ were discharged to LTAC , $50 \%$ to rehab, and none had good GOS (Fig. 4). BSAS $>0$ developed more often in the AFC group (130 times) than the CFC group

\begin{tabular}{|c|c|}
\hline Score & Definition \\
\hline 0 & $\begin{array}{l}\text { None: no shivering noted on palpation of the masseter, } \\
\text { neck, or chest wall }\end{array}$ \\
\hline 1 & Mild: shivering localized to the neck and/or thorax only \\
\hline 2 & $\begin{array}{l}\text { Moderate: shivering involves gross movement of the } \\
\text { upper extremities (in addition to neck and thorax) }\end{array}$ \\
\hline 3 & $\begin{array}{l}\text { Severe: shivering involves gross movements of the } \\
\text { trunk and upper and lower extremities }\end{array}$ \\
\hline
\end{tabular}

Figure 1. Bedside shivering assessment scale (BSAS). 


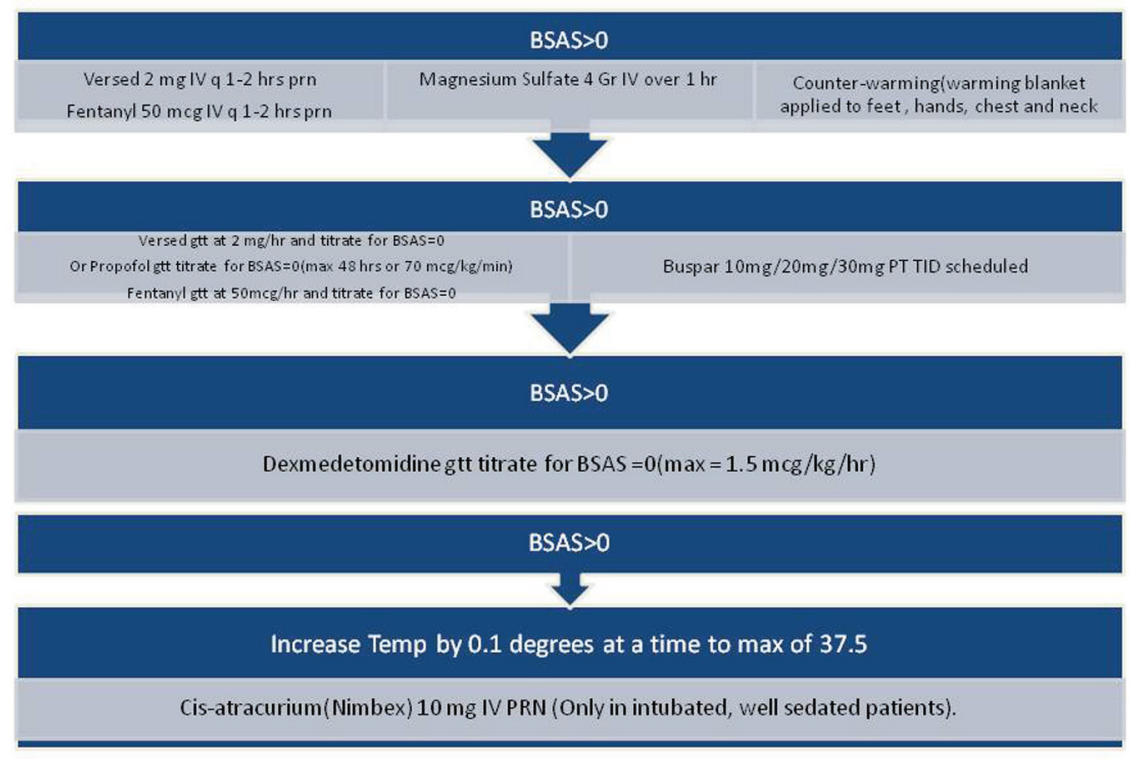

Figure 2. Stepwise approach to treatment of shivering (BSAS > 0).

Table 2. Fever Burden Between the Two Study Groups

\begin{tabular}{llllll}
\hline FB & n & Day $\mathbf{1}$ & Day 2 & Day 3 & Day 4 \\
\hline AFC, h, SD & 8 & $4.0( \pm 3.2)$ & $4.3( \pm 3.5)$ & $3.6( \pm 2.9)$ & $4.2( \pm 3.3)$ \\
CFC, h, SD & 4 & $7.0( \pm 5.2)$ & $7.7( \pm 2.9)$ & $5.3( \pm 6.0)$ & $4.8( \pm 4.6)$ \\
\hline
\end{tabular}

FB: fever burden; AFC: advanced fever control; CFC: conventional fever control.

(two times) (Table 3).

\section{Discussion}

Fever after TBI is common. In one study, up to $44 \%$ of pa- tients with TBI had a tympanic temperature of $38.5^{\circ} \mathrm{C}$ or more within the first 2 days after injury [5]. Up to $73 \%$ of patients developed a core temperature more than $38.4{ }^{\circ} \mathrm{C}$ in another study [15]. Temperature more than $38{ }^{\circ} \mathrm{C}$ occurred in up to $67 \%$ of patients with TBI in the first $72 \mathrm{~h}$ [3], and in up to $78 \%$ in neurocritical care patients in general during their ICU stay

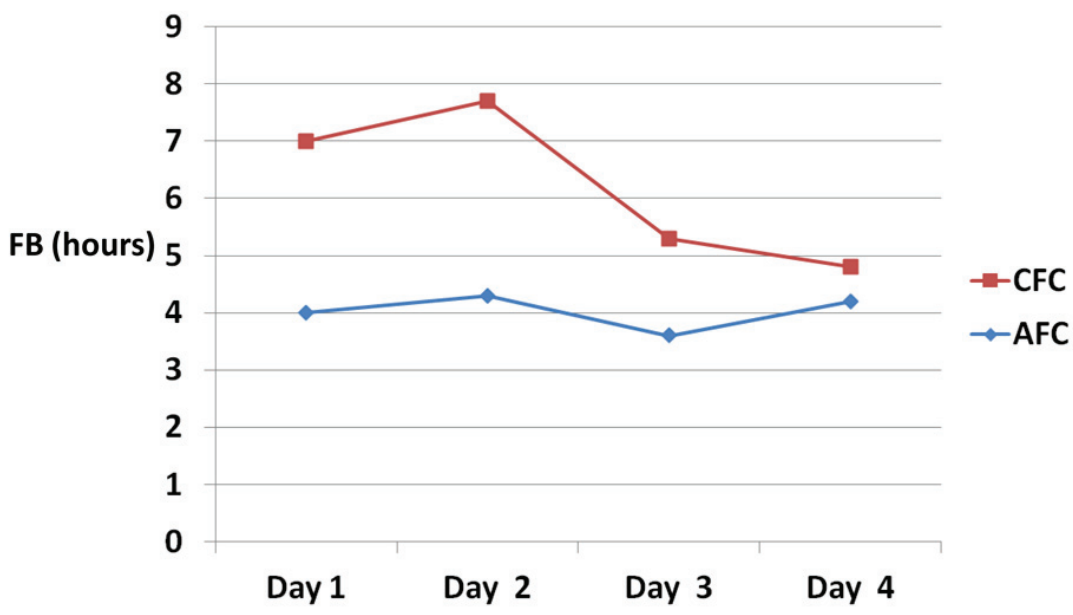

Figure 3. Fever burden between the two study groups (graph). 


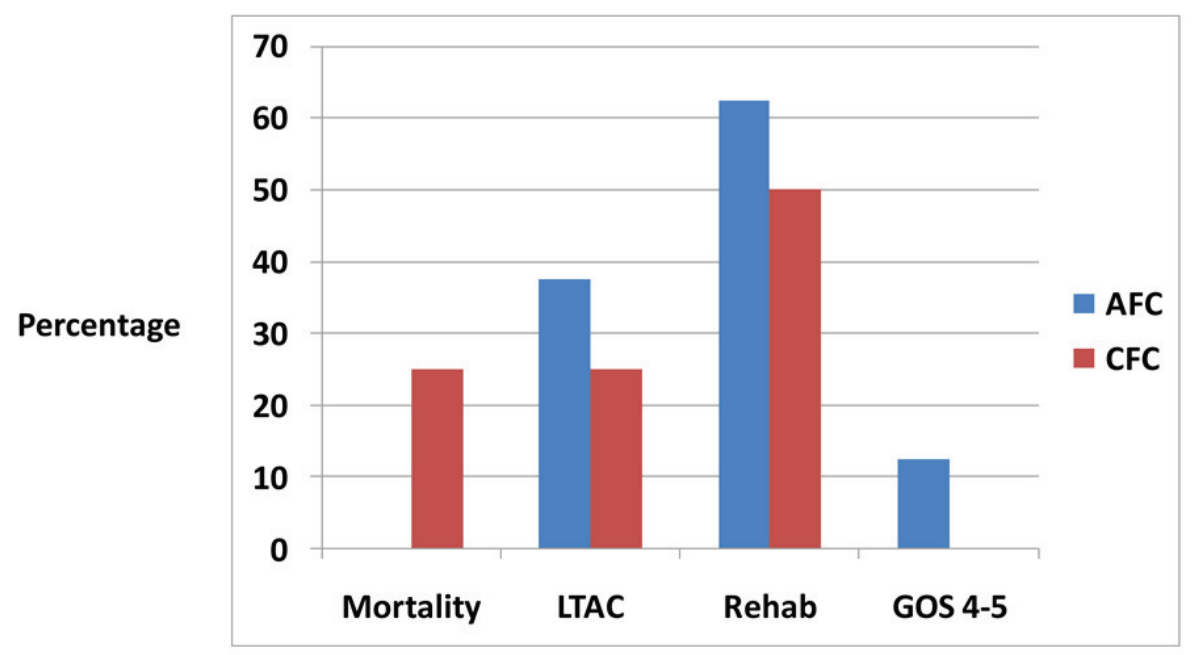

Figure 4. Comparison of outcomes between the two study groups.

[16]. Hyperthermia following TBI is associated with a longer ICU length of stay and worsened neurologic outcomes [5-10].

This study demonstrates that fever prophylaxis via induced normothermia reduces FB in patients with severe TBI as compared to CFC with acetaminophen and cooling blankets. There were no differences in complications between the two groups, like arrhythmias, hyperglycemia episodes, hypotension, hypoxia, days on mechanical ventilation, need for vasopressors, or infectious complications (data not shown). Our study is strengthened by the use of the validated BSAS to evaluate for shivering. AFC was associated with more shivering episodes and thus required more interventions to treat shivering, most of which was in the form of sedative medications. Shivering results in sharp increases in resting energy expenditure and in the rate of oxygen consumption. These findings have previously been validated with the use of indirect calorimetry $[17,18]$. Left uncontrolled, shivering can defeat the cooling process and eliminate the potential benefits of induced normothermia [19] and in extreme cases may be more detrimental than fever itself [20]. Thus, the metabolic consequences of shivering may become the limiting step in demonstrating the benefits of induced normothermia. The use of more sedatives can also have a negative impact on length of stays and neurologic outcomes. This study is underpowered to evaluate these outcomes. This study is limited by the small number of patients. Another limitation of the study is the inability to decipher how much the control of shivering actually affected FB, since shivering itself can lead to heat generation and fever, which could be a confound- ing factor. The AFC technology used (Arctic Sun; Medivance, Inc., Louisville, $\mathrm{CO}, \mathrm{USA}$ ) is a more expensive treatment than CFC methodologies, and thus improved outcomes will need to be documented before such expensive technologies can be adopted as standard of care.

\section{Conclusion}

The elimination of the burden of fever in the first 4 days after severe TBI is feasible and does not appear to be associated with a higher rate of complications. However, AFC was associated with more frequent episodes of shivering, and thus sedative use. Before adopting AFC as standard care for febrile patients with severe TBI, a prospective randomized study comparing the impact of a CFC to an AFC approach on clinical outcomes is warranted, with an emphasis on the impact of shivering on outcome.

\section{Acknowledgement}

None.

\section{Declaration of Interest}

Medivance/BARD provided surface cooling device to study

Table 3. Incidence of BSAS > 0 Between the Two Study Groups

\begin{tabular}{lllllll}
\hline BSAS $>$ 0 & n & Day $\mathbf{1}$ & Day 2 & Day 3 & Day 4 & Total $(96$ h) \\
\hline AFC & 8 & 40 & 40 & 40 & 10 & 130 \\
CFC & 4 & 1 & 1 & 0 & 0 & 2 \\
\hline
\end{tabular}

BSAS: bedside shivering assessment scale; AFC: advanced fever control; CFC: conventional fever control. 
participants and a small grant for study expenses. There was no involvement of industry in any stages of planning, execution, or analysis of this study. All authors report that no potential conflicts of interest exist with any companies/organizations whose products or services may be discussed in this article.

\section{References}

1. Ghajar J. Traumatic brain injury. Lancet. 2000;356(9233):923-929.

2. Rutland-Brown W, Langlois JA, Thomas KE, Xi YL. Incidence of traumatic brain injury in the United States, 2003. J Head Trauma Rehabil. 2006;21(6):544-548.

3. Soukup J, Zauner A, Doppenberg EM, Menzel M, Gilman C, Bullock R, Young HF. Relationship between brain temperature, brain chemistry and oxygen delivery after severe human head injury: the effect of mild hypothermia. Neurol Res. 2002;24(2):161-168.

4. Sadaka F, Veremakis C. Therapeutic hypothermia for the management of intracranial hypertension in severe traumatic brain injury: a systematic review. Brain Inj. 2012;26(7-8):899-908.

5. Geffroy A, Bronchard R, Merckx P, Seince PF, Faillot T, Albaladejo P, Marty J. Severe traumatic head injury in adults: which patients are at risk of early hyperthermia? Intensive Care Med. 2004;30(5):785-790.

6. Suz P, Vavilala MS, Souter M, Muangman S, Lam AM. Clinical features of fever associated with poor outcome in severe pediatric traumatic brain injury. J Neurosurg Anesthesiol. 2006;18(1):5-10.

7. Diringer MN, Reaven NL, Funk SE, Uman GC. Elevated body temperature independently contributes to increased length of stay in neurologic intensive care unit patients. Crit Care Med. 2004;32(7):1489-1495.

8. Soukup J, Zauner A, Doppenberg EM, Menzel M, Gilman C, Young HF, Bullock R. The importance of brain temperature in patients after severe head injury: relationship to intracranial pressure, cerebral perfusion pressure, cerebral blood flow, and outcome. J Neurotrauma. 2002;19(5):559-571.

9. Jones PA, Andrews PJ, Midgley S, Anderson SI, Piper IR, Tocher JL, Housley AM, et al. Measuring the burden of secondary insults in head-injured patients during inten- sive care. J Neurosurg Anesthesiol. 1994;6(1):4-14.

10. Jiang JY, Gao GY, Li WP, Yu MK, Zhu C. Early indicators of prognosis in 846 cases of severe traumatic brain injury. J Neurotrauma. 2002;19(7):869-874.

11. Schwab S, Spranger M, Aschoff A, Steiner T, Hacke W. Brain temperature monitoring and modulation in patients with severe MCA infarction. Neurology. 1997;48(3):762767.

12. Henker RA, Brown SD, Marion DW. Comparison of brain temperature with bladder and rectal temperatures in adults with severe head injury. Neurosurgery. 1998;42(5):10711075 .

13. Badjatia N, Strongilis E, Gordon E, Prescutti M, Fernandez L, Fernandez A, Buitrago M, et al. Metabolic impact of shivering during therapeutic temperature modulation: the Bedside Shivering Assessment Scale. Stroke. 2008;39(12):3242-3247.

14. Jennett B, Bond M. Assessment of outcome after severe brain damage. Lancet. 1975;1(7905):480-484.

15. Stocchetti N, Rossi S, Zanier ER, Colombo A, Beretta L, Citerio G. Pyrexia in head-injured patients admitted to intensive care. Intensive Care Med. 2002;28(11):15551562.

16. Rossi S, Zanier ER, Mauri I, Columbo A, Stocchetti N. Brain temperature, body core temperature, and intracranial pressure in acute cerebral damage. J Neurol Neurosurg Psychiatry. 2001;71(4):448-454.

17. Hardy JD, Stolwijk JA. Partitional calorimetric studies of man during exposures to thermal transients. J Appl Physiol. 1966;21(6): 1799-1806.

18. Claessens-van Ooijen AM, Westerterp KR, Wouters L, Schoffelen PF, van Steenhoven AA, van Marken Lichtenbelt WD. Heat production and body temperature during cooling and rewarming in overweight and lean men. Obesity (Silver Spring). 2006;14(11):1914-1920.

19. Badjatia N, Kowalski RG, Schmidt JM, Voorhees ME, Claassen J, Ostapkovich ND, Presciutti M, et al. Predictors and clinical implications of shivering during therapeutic normothermia. Neurocrit Care. 2007;6(3):186191.

20. Horvath SM, Spurr GB, Hutt BK, Hamilton LH. Metabolic cost of shivering. J Appl Physiol. 1956;8(6):595602 . 